\title{
La construcción de la memoria colectiva del conflicto armado en Colombia desde el video universitario $(2005-2014)^{*}$
}

\author{
The Construction of the Collective Memory of the Armed Conflict in Colombia based on College Video-Making \\ (2005-2014) \\ A construção da memória coletiva do conflito armado na Colômbia desde o vídeo universitário (2005-2014)
}

\author{
Maria Urbanczyk ${ }^{\mathrm{a}}$ \\ Pontificia Universidad Javeriana, Colombia \\ murbanczyk@javeriana.edu.co \\ ORCID: http://orcid.org/0000-0003-0574-8600
}

DOI: https://doi.org/10.11144/Javeriana.syp38-75.cmcc

Fecha de recepción: 30 Marzo 2018

Fecha de aprobación: 30 Julio 2019

Fecha de publicación: 15 Noviembre 2019

\section{Resumen:}

Este artículo pretende mostrar cómo se construyen las memorias del conflicto armado en Colombia desde las narrativas audiovisuales universitarias en el período 2005-2014. Hay que aclarar que, dependiendo del formato audiovisual, los videos evidencian diferentes propósitos narrativos, mientras que los cortometrajes de ficción se centran en los cuestionamientos éticos. Los documentales además de visibilizar los acontecimientos traumáticos desde los recuerdos de las víctimas, van más allá, relatando los intentos por superar los traumas a través del arte y el contacto con la naturaleza, dándole apertura a unos nuevos horizontes de vida pacífica. Llama la atención que los videos experimentales manejan lenguajes más arriesgados, que penetran la conciencia del espectador a partir de denuncias simbólicas, dirigidas a descubrir las maléficas alianzas entre la violencia, la política y los medios de comunicación al servicio de grandes capitales multinacionales. Por ende, a los llamados a repensar la ética y la realidad, se les suma otro, centrado en repensar la política, todos estos articulados alrededor de la idea común de no repetición.

Palabras clave: narrativa audiovisual, memoria colectiva, conflicto armado, jóvenes universitarios.

\section{Abstract:}

This article seeks to show how the memories of the Colombian armed conflict are constructed based on college audiovisual narratives during 2005-2014. Clearly, videos evince different narrative purposes according to the audiovisual format they used; while the fiction short films focus on ethical questioning. Documentaries do more than displaying the traumatic events from the victim's memories; they also narrate the efforts to overcome those traumas through the art and the contact with nature. It provides an opening to new horizons of a pacific life. It is noticeable that experimental videos use more audacious languages that penetrate the viewer's conscience with symbolic denunciation intended to disclose maleficent alliances between politics, violence and the media that serve the big multinational capitals. Therefore, something is added the calls to rethink both the ethics and the reality, to rethink the politics. All this is articulated around a common idea of no repetition.

Keywords: audiovisual narrative, collective memory, armed conflict, college youth.

\section{Resumo:}

Este artigo visa mostrar como as memórias do conflito armado na Colômbia são construídas desde as narrativas audiovisuais universitárias no período 2005-2014. É preciso esclarecer que, dependendo do formato audiovisual, os vídeos demonstram diferentes propósitos narrativos, enquanto os curtas de ficção focam-se nos questionamentos éticos. Os documentários, além de visibilizar os acontecimentos traumáticos desde as lembranças das vítimas, vão além, relatando as tentativas de superar os traumas através da arte e o contato com a natureza, dando abertura a novos horizontes de vida pacífica. Chama a atenção que os vídeos experimentais usam linguagens mais arriscadas, que penetram a consciência do espectador a partir de denúncias simbólicas, encaminhadas a descobrir as maléficas alianças entre violência, política e mídia ao serviço de grandes capitais multinacionais. Por tanto, aos chamados a repensar ética e realidade, se acrescenta mais um, centrado em repensar a política, todos eles articulados em torno da ideia comum de não repetição.

Palavras-chave: narrativa audiovisual, memória coletiva, conflito armado, jovens universitários.

Notas de autor: 


\section{Introducción}

El interés de esta fase de investigación se centró en comprender cómo se construyen las memorias del conflicto armado en Colombia a través de las narrativas audiovisuales universitarias en el período de 2005 a 2014. Para realizar este estudio, se acudió a los trabajos de video (cortometrajes de ficción, documentales y otros formatos, conformados por animaciones, videos experimentales y videoclips), exhibidos en el marco de la Muestra Audiovisual Universitaria Ventanas, organizada anualmente por la Facultad de Comunicación y Lenguaje de la Pontificia Universidad Javeriana de Bogotá.

Dicha muestra presenta los productos audiovisuales de los estudiantes (tanto trabajos de grado, como ejercicios de clase) de diferentes carreras de los centros de educación superior de todo el país. Es una de las pocas muestras audiovisuales universitarias a nivel nacional que ha logrado mantenerse tantos años (desde 2005 abierta a nivel nacional), guardando su periodicidad y el enfoque académico que privilegia el espíritu del encuentro y del debate sobre la idea de la competencia. Vale la pena resaltar que este evento no es un concurso, sino una muestra que cuenta con un proceso previo de curaduría por parte de los expertos del área audiovisual (críticos, académicos, directores de cine, productores audiovisuales, figuras de la industria televisiva), con el objetivo de seleccionar un material de calidad para la proyección, que permita visibilizar las tendencias de la creación audiovisual universitaria en el país y reflexionar sobre ellas.

Al indagar por la construcción de la memoria, no se trata de asumirla como un hecho culminado y estático. Se pretende comprender el pasado desde la perspectiva propuesta por Vich y Zavala, según la cual "el pasado no es algo anterior al presente sino una dimensión interior de éste. No está atrás sino adentro” (2004, p. 18). Por lo tanto, estudiar el palimpsesto audiovisual universitario posibilita acceder a la multiplicidad de las interpretaciones de las realidades vividas e imaginadas, lo que viabiliza una mejor comprensión de lo humano, social e identitario, en Colombia.

Conjuntamente a estas dos dimensiones, el pasado y el presente, relacionadas con la construcción de la memoria como interpretación, hay que añadir una más que es el futuro. Herrera resalta que:

[...] toda interpretación tiene una dimensión práctica que no puede separar y que no sólo (sic) tiene que ver con el presente, sino con el futuro. La interpretación se entiende así también como proyecto; es decir, como parte de aquello que podemos llegar a ser [...]. La pregunta por la historicidad y sus olvidos no es sólo objeto de las ciencias históricas, sino que hace parte de todo intento por comprender cualquier fenómeno social. (2010, pp. 183-184)

La relación con el futuro y el enfoque proyectivo de la interpretación cobran una especial importancia en referencia a los productos realizados por los estudiantes, quienes a través de sus narrativas críticas y denuncias, no solamente interpelan al pasado, sino que expresan sus anhelos, esperanzas, imaginarios, inquietudes, incertidumbres, así como también proponen las posibles soluciones de conflictos, mediante luchas simbólicas en pro del mejoramiento de las condiciones de vida de la sociedad colombiana.

Vale la pena resaltar que con frecuencia los trabajos audiovisuales universitarios no logran transcender las aulas de clase, quedan archivados u olvidados, al cumplir su propósito de ser un ejercicio de clase. La misma academia parece desconocer, y por tanto subestimar, el valor que tienen estas obras como constructoras del sentido y la memoria. Teniendo en cuenta lo anterior, se hace necesario investigar las narrativas audiovisuales universitarias, generar las culturas de visibilización y debate alrededor de dicho material, lo que puede constituir un gran aporte a estudiantes, investigadores y espectadores, en la comprensión de la complejidad de lo social, lo humano y lo artístico. 


\section{Articulaciones entre la memoria y la narrativa audiovisual universitaria}

La memoria es algo inabarcable que se encuentra en permanente construcción, y aunque se refiere al pasado, se configura en el presente en los procesos, subjetivos y fragmentados, de recordar que dependen de los intereses y las necesidades actuales de los que recuerdan.

La memoria colectiva es un capital social intangible. Sólo (sic) en el nivel simbólico se puede hablar de una memoria colectiva, como el conjunto de tradiciones, creencias, rituales y mitos que poseen los miembros pertenecientes a un determinado grupo social y que determinan su adscripción al mismo. (Colmeiro, 2005, p. 15)

Uno de los posibles acercamientos a la memoria colectiva como capital simbólico se puede hacer desde el análisis de las narrativas, en el caso específico de la presente investigación, las audiovisuales, que involucran diversos aspectos como lenguajes, contenidos, traductibilidad, imágenes, medios, identidades, mentalidades, corporalidades, subjetividades, entre otros.

Al hacer la apuesta por la reconstrucción de la memoria colectiva desde las narrativas conviene referirse a los trabajos del sociólogo francés Maurice Halbwachs, quien, en la primera mitad del siglo XX, abordó el concepto de la memoria colectiva desde tres diferentes enfoques: la memoria individual que es socialmente determinada, la memoria generacional y, finalmente, la memoria entendida como la transmisión del saber cultural. Lo que diferencia la mirada de Halbwachs de sus antecesores y contemporáneos, es la apuesta por la construcción colectiva de la memoria, que se realiza a partir de la interacción y comunicación. Los seres humanos consolidan la memoria y el recuerdo en relación con los marcos sociales (la gente que los rodea). Además, según el autor "cada memoria individual es un punto de vista sobre la memoria colectiva" (Halbwachs, 2005, p. 50). De tal manera, existe una interdependencia entre las memorias individuales y colectivas. No obstante, hay que tener en cuenta que cada ser humano pertenece a diferentes grupos sociales (familia, vecindad, comunidad religiosa, círculo educativo, equipo de trabajo, clase social, etc.), en consecuencia, los recuerdos individuales están condicionados por las mediaciones y combinaciones de todas las pertenencias grupales.

Si la memoria colectiva se asume desde la mirada de la construcción social, a partir de los procesos de interacción que permiten establecer la continuidad del pasado con el presente y el vínculo entre el individuo y el grupo social al cual pertenece, entonces, profundizar en el estudio de narrativas comunicativas puede aportar a la comprensión de la complejidad de dicho fenómeno, que además es fundamental para la consolidación de la identidad cultural. Sin embargo, es necesario resaltar que la comunicación debe ser vista, no únicamente desde la perspectiva de los medios, sino desde las múltiples mediaciones y fenómenos mediales en torno a las interacciones informacionales y comunicativas.

Estas interacciones se convierten en el campo de batalla por la hegemonía, donde se sitúan los usos y abusos de la memoria que condicionan la aparición y existencia de diferentes tipos de memorias, como dividida, fragmentada, manipulada u obligada. Al trasladar la reflexión al terreno de los abusos, surgen los interrogantes por la responsabilidad, la ética, el duelo y el perdón. Estos se refieren sobre todo a la memoria histórica que forma parte de la memoria colectiva y se caracteriza "por una conceptualización crítica de acontecimientos de signo histórico compartidos colectivamente y vivos en el horizonte referencial del grupo" (Colmeiro, 2005, p. 18).

Este último autor al profundizar en el concepto de la memoria histórica lo vincula directamente con la conciencia histórica de la memoria, por "su naturaleza auto-reflexiva sobre la función de la memoria". Esta naturaleza autorreflexiva, según Manuel Reyes Mate, se transfiere a los deberes de la memoria que, después de la Segunda Guerra Mundial, dejó de ser vista únicamente como productora de los sentimientos, convirtiéndose en gestora de los conocimientos. Además, poner el énfasis en el sufrimiento humano, que hasta entonces ha sido ocultado por la ciencia, posibilitó a la memoria una autorreconfiguración, en el resultado de la cual la voz de las víctimas se ha ubicado en el centro de interés investigativo. Desde esta perspectiva, 
los deberes de memoria se refieren a la necesidad de repensar el pasado, la realidad, la ética, la estética, las relaciones entre política y violencia, y, por ende, un urgente compromiso de repensarse colectivamente como humanidad (Mate, 2012, pp. 40-42).

Sobre dicho deber de participar en el proceso de repensarse y reconstruir la memoria colectiva habla también Paul Ricoeur en el libro La memoria, la historia y el olvido, al hacer un llamado a cada uno de los miembros de la sociedad: "aquí, el lema de las Luces: ¡sapere aude!, ¡sal de la minoría!, puede reescribirse: ¡atrévete a crear relato!, ja narrar por ti mismo!” (2008, p. 573). Precisamente, los estudiantes que realizan los productos audiovisuales asumen esta labor de contar la realidad y construir la memoria colectiva, incluyendo la histórica, desde lo particular, lo íntimo, lo oculto, lo silenciado, presentando en sus relatos las problemáticas que los inquietan o indignan, con frecuencia enfatizando en el conflicto armado en Colombia desde la perspectiva de un pasado común traumático para toda la sociedad que merece ser repensado, contado, visibilizado y, por consiguiente, recordado.

Las narrativas audiovisuales universitarias, al igual que otras narrativas mediáticas, cuando cuentan las historias, cumplen varias funciones: por un lado, la función mimética de imitar la realidad al reproducirla, salvaguardando ciertas característica y contextos históricos, sociales, políticos, económicos, culturales o del ámbito ético o estético, propios de la época, y, por el otro lado, la función proyectista que consiste en idear las nuevas tendencias y modelos de comportamiento a partir de la visibilización de los imaginarios, las sensibilidades, los gustos, las tensiones o las rupturas emergentes en las identidades culturales, que impactarán la configuración de las conductas reales de los espectadores hacia el futuro. Por esto, dichas narrativas pueden ser vistas desde la perspectiva de un fenómeno que Carrithers describe como "un pensamiento narrativo que no consiste solamente en la narración de historias, sino en la comprensión de redes complejas de acontecimientos y actitudes" (1995, pp. 120-121). Al entrar en el diálogo con la variedad de interpretaciones de las realidades vividas e imaginadas, en esta relación conflictiva entre los discursos hegemónicos y alternativos, los jóvenes universitarios se convierten en sujetos políticos con una capacidad constituyente "para dar sentido y construir además de lo posible, lo deseable; aquí, tiene cabida la memoria, la resistencia, la imaginación, la creatividad, la utopía, la multiplicidad de saberes y experiencias que organizan nuestra existencia individual y colectiva" (Cubides, 2011, p. 24).

\section{Apuesta metodológica}

Al visualizar el material completo de la Muestra Ventanas (2005-2014), compuesto por 298 videos, y al confrontarlo con el objetivo principal de la investigación, enfocado en comprender cómo se construyen las memorias del país (en esta fase particular, las memorias del conflicto armado), se realizó una delimitación del material pensando en un número representativo de 100 videos en total, repartidos en 10 videos por año: cinco (5) documentales, tres (3) cortometrajes de ficción y dos (2) de otros formatos, enfatizando en el documental como formato que ha tenido la mayor representatividad cuantitativa en el marco de la Muestra, y cuyo objetivo gira en torno a la representación de la realidad. Vale la pena resaltar que el proceso de la selección no fue fácil, y aunque los factores correspondientes al contenido y al mensaje de las obras han sido decisivos, se hizo el intento por reflejar la mayor variedad, teniendo en cuenta la procedencia de las obras (diversidad de universidades).

Dentro de los 100 videos seleccionados, la problemática del conflicto armado en Colombia está presente en 34, en 18 de los cuales se muestra de manera directa como problemática central de las narrativas, mientras que en los 16 casos restantes se convierte en el telón de fondo para los hechos desarrollados en la pantalla, funcionando en forma de alusiones, tramas secundarias, contextos, recuerdos, frases sueltas, ambientes que influyen en las narrativas, sin embargo, no alcanzan a ser su hilo conductor (presentación indirecta). 
A partir de la revisión bibliográfica sobre la articulación entre la memoria colectiva y las narrativas, reforzada por las ideas de Franco Moretti quien considera que el término distant reading se entiende como "un método donde la distancia no es un obstáculo para el conocimiento, sino una de sus formas específicas. La distancia, ciertamente, permite apreciar menos detalles, pero ayuda a comprender mejor las relaciones, los patterns, las formas" (Moretti, 2007, pp. 9-10), se procedió a la elaboración de una matriz de análisis, aplicable a todos los formatos audiovisuales presentes en la Muestra. Se trata de una matriz abierta a las observaciones y los ajustes necesarios a la hora de la interpretación, capaz de arrojar las pistas para identificar ciertas tendencias que avizoran las interrelación entre las narrativas audiovisuales, la construcción de la memoria colectiva del país y los procesos de construcción identitaria de los jóvenes realizadores universitarios y construida con base en los siguientes aspectos:

- Información general: título del video, formato, año de realización, año de presentación en la Muestra Ventanas, universidad, duración, palabras clave, sinopsis.

- Personajes: franja etaria, perfil étnico, familia, tipo de familia, roles, relaciones entre los personajes, intereses, luchas, sueños, miedos, valores.

- Acontecimientos: tema central, subtema, conflicto armado, presentación del conflicto, enfoque, construcción de acontecimiento, uso del material audiovisual, narrativa predominante, símbolos y metáforas.

- Condiciones espaciales: lugar (selección de lugares desde donde se cuenta, creación de espacios).

- Condiciones temporales: tiempo (organización del tiempo narrativo).

- Memoria colectiva: tipo de memoria, herramientas narrativas de construcción de memoria, personajes referentes, hechos, otros referentes, tipo de archivo.

- Universos: articulación de los factores del ámbito axiológico, político y estético.

Para poder proceder a la lectura crítica de los resultados de la aplicación de la matriz de análisis y establecer los vínculos con los hechos y acontecimientos (reales) investigados y documentados previamente, entendidos desde la perspectiva de los referentes históricos del conflicto armado en Colombia, se acudió a la revisión del Informe General del Centro Nacional de Memoria Histórica ;Basta ya! Colombia: memorias de guerra $y$ dignidad (CNMH, 2013). Esta revisión permitió identificar muchas similitudes entre la documentación recolectada por el equipo investigativo del CNMH y las percepciones de los jóvenes realizadores audiovisuales sobre el conflicto armado, que se reflejan en la pantalla. Adicionalmente, esta lectura fue reforzada y puesta en diálogo con las ideas del filósofo español, Manuel Reyes Mate, especializado en la memoria y sus profundos vínculos con el sufrimiento humano.

\section{Presentación directa del conflicto armado en los videos universitarios}

Para los efectos de este artículo, se presentarán los resultados de la lectura de la matriz de análisis concerniente a las 18 obras audiovisuales que presentan el conflicto armado de manera directa y que proceden de diferentes centros educativos: cuatro trabajos de la Universidad del Valle (Cali), dos de la Pontificia Universidad Javeriana de Bogotá, dos de la Escuela de Cine Black María (Bogotá), dos de la Universidad Nacional de Colombia (Bogotá), dos de la Universidad del Magdalena (Santa Marta), uno de la Universidad Manuela Beltrán (Bogotá), uno de la Universidad de Antioquía (Medellín), uno de la Universidad Minuto de Dios (Uniminuto de Bogotá), uno de la Universidad del Cauca (Popayán) y uno de la Universidad de Medellín (Medellín). Los trabajos están repartidos en todos los años, desde 2005 hasta el 2014, a excepción de la Muestra del año 2007 cuando no figura ningún trabajo dedicado directamente a esta problemática. En lo relativo a los formatos, la distribución de los 18 trabajos que presentan el conflicto armado en Colombia de manera directa es la siguiente: ocho documentales, ocho ficciones y dos trabajos experimentales (tabla 1). 
TABLA 1

Distribución de los 18 trabajos que presentan el conflicto armado en Colombia de manera directa

\begin{tabular}{|c|c|c|}
\hline \multicolumn{3}{|c|}{ Cortometrajes de ficción } \\
\hline $\begin{array}{l}\text { Título, año de presentación en la } \\
\text { Muestra Ventanas y Universidad }\end{array}$ & Sinopsis & Realizadores \\
\hline $\begin{array}{l}\text { Maniana piensa en mi (2006) } \\
\text { Pontificia Universidad Javeriana } \\
\text { (Bogotá) }\end{array}$ & $\begin{array}{l}\text { Un secuestrado está encerrado en la celda. Vienen unos uniformados } \\
\text { para ejecutarlo. El hombre escapa y corre a una casa donde se } \\
\text { encuentra con su amada (imaginación). Al final se ven los brazos } \\
\text { atados en el suelo y los uniformados alejándose después de cjecutar al } \\
\text { hombre. }\end{array}$ & Sebastián Valencia \\
\hline $\begin{array}{l}\text { Donde el vionto se devuelve (2008) } \\
\text { Escuela de Cine Black Maria (Bogotá) }\end{array}$ & $\begin{array}{l}\text { Una familia rural es asaltada por un grupo armado. Los asaltantes } \\
\text { obligan al padre de la familia a disparar a su propio hijo. La familia (ya } \\
\text { sin hijo) abandona su casa y su tierra, y se dirige a la ciudad. (Una } \\
\text { simbólica historia del desplazamiento forzado en Colombia). }\end{array}$ & David Villegas \\
\hline $\begin{array}{l}\text { Un, dos, tres por Rafael (2009) } \\
\text { Universidad Manuela Beltrán (Bogotá) }\end{array}$ & $\begin{array}{l}\text { Jugando a escondidas, los nińos entran a una casa abandonada donde } \\
\text { encuentran a un fantasma del pasado: un nińo que vivía en esta y fue } \\
\text { asesinado alli junto con sus padres durante el Bogotazo. }\end{array}$ & $\begin{array}{l}\text { Carolina Rincón } \\
\text { Bedoya; Sebastián } \\
\text { Rivera Martínez; } \\
\text { Andrea Isaza } \\
\text { Arismendi; Nathaly } \\
\text { Castańo; David } \\
\text { Zambrano Devis; Juan } \\
\text { Camilo Rocha Ramírez }\end{array}$ \\
\hline $\begin{array}{l}\text { Permiso para soñar } \\
\text { (2010) } \\
\text { Universidad del Magdalena (Santa } \\
\text { Marta) }\end{array}$ & $\begin{array}{l}\text { Luisa es una niña campesina que sueña con ser bailarina y viajar a } \\
\text { Bogotá para participar en un concurso de baile. El padre de la niña se } \\
\text { opone a estos planes. Luisa va a los ensayos de baile a escondidas del } \\
\text { padre. Para no ser descubierta escoge un camino peligroso y pisa una } \\
\text { mina antipersonal. Luisa no alcanza a enterarse que ganó el concurso } \\
\text { y fue seleccionada para viajar a Bogotá a bailar. }\end{array}$ & $\begin{array}{l}\text { Claudia Iguarán } \\
\text { Manjarres; Carlos } \\
\text { Navarro Montes }\end{array}$ \\
\hline $\begin{array}{l}\text { Los médicos también mueren } \\
\text { (2010) } \\
\text { Universidad del Magdalena (Santa } \\
\text { Marta) }\end{array}$ & $\begin{array}{l}\text { En 1996, un grupo armado paramilitar asesina a una pareja. } 14 \text { ańos } \\
\text { después los victimarios siguen con las mismas prácticas violentas, sin } \\
\text { embargo, llega la venganza (uno de los sobrevivientes, médico, toma la } \\
\text { justicia en sus manos). }\end{array}$ & $\begin{array}{l}\text { David Paternina; } \\
\text { Nelson Toncel; } \\
\text { Natahlie Forero }\end{array}$ \\
\hline $\begin{array}{l}\text { La escuela } \\
\text { (2011) } \\
\text { Universidad Nacional de Colombia } \\
\text { (Bogotá) }\end{array}$ & $\begin{array}{l}\text { Un nińo campesino regresa a su escuela destruida durante el conflicto } \\
\text { armado, recordando y ańorando la época cuando podía estudiar. }\end{array}$ & Jaison Murillo \\
\hline $\begin{array}{l}\text { El miedo y la gallina } \\
\text { (2012) } \\
\text { Universidad de Antioquia (Medellin) }\end{array}$ & $\begin{array}{l}\text { Marta es una campesina vieja que adora a su gallina. Cuando un } \\
\text { paramilitar le ordena prepararle un caldo de esta gallina, Marta hace } \\
\text { todo lo posible para salvarla, inclusive pierde la vida. }\end{array}$ & Freddy Fortich Vásquez \\
\hline $\begin{array}{l}\text { Tiempo de memorias } \\
\text { (2013) } \\
\text { Universidad de la Sabana (Bogotá) }\end{array}$ & $\begin{array}{l}\text { A ráz del asesinato del padre de Laura, ella con la mamá se ven } \\
\text { obligadas a abandonar su casa. La salida del campo se torna aún más } \\
\text { dificil porque a Laura le toca despedirse y separarse de su amigo } \\
\text { Andrés. }\end{array}$ & $\begin{array}{l}\text { Vanesa Monroy; Laura } \\
\text { Pineda }\end{array}$ \\
\hline
\end{tabular}

Fuente: elaboración propia 
TABLA 1 (CONT.)

Distribución de los 18 trabajos que presentan el conflicto armado en Colombia de manera directa

\begin{tabular}{|c|c|c|}
\hline \multicolumn{3}{|c|}{ Documentales } \\
\hline $\begin{array}{l}\text { Título, ańo de presentación en la } \\
\text { Muestra Ventanas y Universidad }\end{array}$ & Sinopsis & Realizadores \\
\hline $\begin{array}{l}\text { TV o la morada de mis imágenes } \\
\text { (2005) } \\
\text { Universidad del Valle (Cali) }\end{array}$ & $\begin{array}{l}\text { La joven caleńa, estudiante de comunicación social, cuenta su vida a } \\
\text { través de los recuerdos televisivos. }\end{array}$ & Diana Giraldo \\
\hline $\begin{array}{l}\text { Welcome to Colombia } \\
\text { (2008) } \\
\text { UNIMINUTO (Bogotá) }\end{array}$ & $\begin{array}{l}\text { Con base en un testimonio se presenta la problemática migratoria, } \\
\text { las deportaciones de los colombianos, la falta de politicas públicas } \\
\text { migratorias en Colombia. }\end{array}$ & Lorena Medellín Fonseca \\
\hline $\begin{array}{l}\text { En el patio de mi casa } \\
\text { (2009) } \\
\text { Universidad de Medellin (Medellin) }\end{array}$ & $\begin{array}{l}\text { Jhon Ferney Giraldo es un joven afectado por una mina } \\
\text { antipersonal, se presenta su recuperación fisica y emocional. } \\
\text { Paralelamente, se desarrolla una obra de teatro sobre la misma } \\
\text { problemática "Quiebrapatas". }\end{array}$ & $\begin{array}{l}\text { Elkin Ariza; Alejandro } \\
\text { López }\end{array}$ \\
\hline $\begin{array}{l}\text { Túnel del Carpio } \\
\text { (2010) } \\
\text { Universidad Nacional de Colombia } \\
\text { (Bogotá) }\end{array}$ & $\begin{array}{l}\text { Un joven colombiano en Suiza desarrolla un proyecto audiovisual } \\
\text { sobre la memoria histórica, caso de la toma del Palacio de Justicia. } \\
\text { Indaga qué queda en la memoria de la gente. }\end{array}$ & Ricardo Pinzón \\
\hline $\begin{array}{l}\text { Las voces del Cauca } \\
\text { (2011) } \\
\text { Universidad del Valle (Cali) }\end{array}$ & $\begin{array}{l}\text { La reconstrucción de la memoria colectiva relacionada con la } \\
\text { masacre de Trujillo (1988-1994) donde hubo } 342 \text { víctimas de } \\
\text { homicidio, tortura y desaparición forzada por parte de una alianza } \\
\text { criminal de narcotraficantes (Cartel del Norte del Valle), } \\
\text { paramilitares y fuerza pública. }\end{array}$ & Ángela Gómez \\
\hline $\begin{array}{l}\text { Rojas Pinilla. Un enigma lleno de } \\
\text { bistorias } \\
\text { (2011) } \\
\text { Pontificia Universidad Javeriana } \\
\text { (Bogotá) }\end{array}$ & $\begin{array}{l}\text { Se presenta el personaje, Gustavo Rojas Pinilla, en el contexto } \\
\text { político de la época. La presentación se basa en las contradicciones } \\
\text { (por un lado, se enfatiza en su gobierno dictatorial, autoritario, pero, } \\
\text { por el otro lado, se muestran sus acciones vanguardistas, la } \\
\text { introducción de la TV en Colombia, los esfuerzos por la paz, los } \\
\text { desarrollos en el área educativa y social). }\end{array}$ & Alejandro Home Velasco \\
\hline $\begin{array}{l}\text { Kew'sx Thegnixsa. Nuestra Mirada } \\
\text { (2012) } \\
\text { Universidad del Valle (Cali) }\end{array}$ & $\begin{array}{l}\text { Se presenta la vida de los nińos de la Escuela Indigena Santa Isabel } \\
\text { (departamento del Cauca); en el fondo, el conflicto armado y la } \\
\text { lucha de resistencia. }\end{array}$ & Mónica Maria Mondragón \\
\hline $\begin{array}{l}\text { La Tierra Floreciente } \\
\text { (2014) }\end{array}$ & $\begin{array}{l}\text { Se presenta la vida cotidiana y la superación del pasado traumático } \\
\text { de la comunidad indigena, desplazada de la Región del Naya por las }\end{array}$ & $\begin{array}{l}\text { Ana Gómez Quintero; } \\
\text { Karen Girón; Quith }\end{array}$ \\
\hline Universidad del Cauca (Popayán) & $\begin{array}{l}\text { AUC en el ańo 2001. Esta comunidad se estableció, gracias a ganar } \\
\text { unas demandas y tutelas, en el Sur-Occidente de Colombia, } \\
\text { organizando el Cabildo Indigena Nasa Kitek Kiwe (Tierra } \\
\text { Floreciente) en el Timbio (Cauca). }\end{array}$ & Maury Perdomo \\
\hline $\begin{array}{l}\text { Al vacio I, II, III } \\
\text { (2006) } \\
\text { Universidad del Valle (Cali) }\end{array}$ & $\begin{array}{l}\text { Una mirada crítica frente a la situación que vive Colombia } \\
\text { (violencia, muerte, sufrimiento, todo a la venta) y al cubrimiento } \\
\text { mediático internacional que se le está dando a esta situación. }\end{array}$ & Oscar Ruíz Navia \\
\hline $\begin{array}{l}\text { Lo mismo } \\
\text { (2009) } \\
\text { Escuela de Cine Black Maria (Bogotá) }\end{array}$ & $\begin{array}{l}\text { El contraste entre los discursos políticos (la politica de seguridad } \\
\text { democrática de Álvaro Uribe), las promesas y la realidad (violenta). }\end{array}$ & Mariana Garcés \\
\hline
\end{tabular}




\section{Similitudes entre el Informe General del Centro Nacional de Memoria Histórica y las narrativas audiovisuales de los estudiantes}

Se presentan a continuación las múltiples coincidencias que se encontraron entre el contenido del Informe General del Centro Nacional de Memoria Histórica, titulado ;Basta ya! Colombia: memorias de guerra y dignidad y los relatos audiovisuales de los jóvenes realizadores colombianos.

\section{Modalidades de violencia}

Se especifican enseguida las principales modalidades de violencia en el marco del conflicto armado colombiano investigadas por el CNMH y presentadas en el Informe General (p. 42).

- los asesinatos selectivos

- las masacres

- las muertes de civiles en acciones bélicas

- los atentados terroristas

- los ataques a poblaciones

- los ataques a bienes civiles

- el secuestro

- la tortura

- la desaparición forzada

- el desplazamiento forzado

- la violencia sexual

- las minas antipersonales

- el reclutamiento ilícito

Todas estas modalidades de violencia están representadas en el conjunto (diferentes formatos) de los trabajos audiovisuales universitarios que forman la Muestra $V e n t a n a s$. Aunque, es de resaltar que en la pantalla no se enfatiza en mostrar la violencia cruda, sino las consecuencias y huellas que deja el conflicto armado en las víctimas, sobre todo en la población civil.

\section{Víctimas y victimarios}

El Grupo de Memoria Histórica (GMH) pudo identificar 405 niños, niñas y adolescentes entre las víctimas de los actores armados, lo que representa el 3,4\% de los casos documentados para el periodo 1980-2012. De hecho, atacar a los niños, niñas y adolescentes en las masacres se convirtió en una acción intencionalmente infligida para devastar a los sobrevivientes y comunicar a los enemigos el colapso de cualquier límite moral en el conflicto armado. En esa misma perspectiva, se inscribe el asesinato de 85 adultos mayores (CNMH, 2013, p. 54).

Los realizadores de los cortometrajes de ficción enfocan sus intereses narrativos precisamente en los más indefensos, en los más silenciados: niños y ancianos. Su escogencia como personajes principales contribuye a la sensibilización del público, logra la empatía con los inocentes e indefensos, despierta toda la gama de cuestionamientos frente a sus vínculos/posicionamientos/reacciones (de la sociedad colombiana, en general) en relación con el conflicto.

Por otra parte, en los cortometrajes de ficción los victimarios no se especifican claramente en la pantalla, y a los espectadores les toca activar sus conocimientos o imaginarios acumulados para poder descifrar quién 
es quién e intentar encasillar a los agresores en alguno de los grupos armados que forman parte del conflicto. Es bien sabido que cada uno de los actores armados ha enfatizado en diferentes prácticas de violencia. En este orden de ideas, cuando en la pantalla aparecen los uniformados, con el pelo largo, secuestrando y asesinando a un hombre, el espectador está propicio a asociarlos sobre todo con los guerrilleros (y en el menor grado con los paramilitares), teniendo en cuenta que:

[...] de los 27.023 secuestros reportados entre 1970 y 2010, las guerrillas son autoras de 24.482 , lo que equivale al 90,6 \%. Los paramilitares han realizado 2541 secuestros, correspondientes al 9,4\%. Lo anterior significa que de cada diez secuestros, aproximadamente, las guerrillas son responsables de nueve y los grupos paramilitares de uno. (CNMH, 2013, p. 37)

Mientras tanto, cuando en la pantalla la población civil es estigmatizada como compuesta de guerrilleros y posteriormente desplazada o asesinada, o cuando se presenta la estrategia de tierra arrasada (CNMH, 2013, p. 39),

[...] que consiste en el ejercicio de la violencia que no solo aniquila a las personas sino que destruye el entorno material y simbólico de las víctimas. De esta manera, el territorio se vuelve inhabitable por la propagación de las huellas de terror, lo que fuerza el éxodo de la población. [...],

los espectadores suelen asociar a los victimarios con los grupos paramilitares. La tendencia de no nombrar claramente a los agresores o referirse a ellos usando el término "esta gente" (gente del mal) está presente en la mayoría de los cortometrajes de ficción. Dicha representación audiovisual encuentra coincidencias con las realidades observadas por el Grupo de Memoria Histórica, que resalta que:

[...]. La dificultad para diferenciar a los actores armados se complementa con la imposición del silencio a las víctimas y a los testigos, con el propósito de impedir la denuncia y obstaculizar la investigación judicial. Todo esto ha redundado en el protagonismo de los mismos actores armados, quienes niegan su responsabilidad en los crímenes perpetrados y desvían la atención de la opinión pública. (CNMH, 2013, p. 33)

Sin embargo, el propósito de los realizadores de los cortometrajes parece no centrarse en la documentación de los acontecimientos, como en el caso de los trabajos documentales, sino en sencillas historias dramatizadas con significado universal, con el propósito de generar en el público un sentimiento de rechazo frente al conflicto y mostrar un claro posicionamiento, según el cual este convierte a la población civil colombiana en víctima, compuesta de personas inocentes que sufren. Esta idea también está en concordancia con lo expuesto en el Informe General del CNMH sobre el número aproximado de los muertos provocados como resultado del conflicto que es 220.000 personas, de los cuales $81,5 \%$ son civiles y el resto, $18,5 \%$, combatientes (CNMH, 2013, p. 32) y sobre el objeto de los ataques, descrito de la siguiente manera:

Todos los actores armados han incorporado el ataque a la población civil como estrategia de guerra. Sin embargo, las modalidades de violencia empleadas y la intensidad de su accionar difieren según las evaluaciones que cada actor hace del territorio, del momento de la guerra y de las estrategias que despliega, dentro de las cuales se implica a la población civil. (CNMH, 2013, p. 34)

$\mathrm{Al}$ revisar las narrativas de todos los cortometrajes de ficción donde se presenta el conflicto de manera directa, se encontraron únicamente dos fechas explícitas: 1948 que se refiere al Bogotazo y 1996 que en la obra audiovisual corresponde a la matanza de una inocente pareja de jóvenes enamorados por parte de los miembros de AUC. Es interesante que en el Informe General del CNMH precisamente se nombra el año 1996 como el comienzo de:

[...] una tendencia explosiva entre 1996 y 2002, en la que el conflicto armado alcanzó su nivel más crítico como consecuencia del fortalecimiento militar de las guerrillas, la expansión nacional de los grupos paramilitares, la crisis del Estado, la crisis económica, la reconfiguración del narcotráfico y su reacomodamiento dentro de las coordenadas del conflicto armado. (CNMH, 2013, p. 33) 
Una de las diversas metáforas del conflicto que los estudiantes recrean en los cortometrajes de ficción es la del secuestro como reflejo de la violencia que vive el país: todo el país está secuestrado, sumergido en la violencia; lo que no se aleja de la realidad vivida en Colombia, donde, según el Informe General del Centro Nacional de Memoria Histórica [CNMH], "80,2 \% del territorio nacional (919 municipios) se vio afectado por el secuestro" (2013, p. 71).

\section{Narrativa testimonial}

En los documentales, al igual que en el Informe del CNMH se le otorga gran importancia al testimonio. Aunque en la presente selección de las narrativas audiovisuales documentales prevalecen los testimonios de las víctimas del conflicto armado, estos se entretejen con la multiplicidad de voces de los realizadores, testigos de los acontecimientos, expertos en el área o simplemente transeúntes.

El hecho de acudir a los testimonios de las víctimas toma un significado especial en los documentales referentes a los acontecimientos que no han sido documentados audiovisualmente con anterioridad o cuya documentación es bastante escasa. Es evidente la estrecha relación entre la ausencia del archivo audiovisual y el lugar del desarrollo de los acontecimientos, así como la gravedad y la crueldad de lo acontecido allí, lo que en los documentales en cuestión corresponde a las zonas rurales, apartadas de los centros urbanos, frecuentemente habitadas por indígenas, donde tuvieron lugar las masacres, asesinatos, violaciones, y donde, junto con las minas antipersonales, fueron sembrados el miedo y el silencio.

\section{Nombrar los hechos por su nombre}

En un país sumergido en el conflicto armado, las disputas alrededor de nombrar adecuadamente los hechos son inseparables de las búsquedas de la verdad y el reconocimiento. Estas complejas disputas, junto con la gran carga emocional, conceptual, simbólica y ética que conllevan, parecen dejar huellas en los estudiantes que intentan expresar su posición frente a esta situación en los trabajos audiovisuales universitarios. Por lo tanto, con frecuencia en los documentales universitarios tienen cabida los ecos de las discusiones y debates existentes en el país: ¿quién es la víctima?, ¿qué término usar: víctima o sobreviviente?, ¿qué pasa en el caso de las víctimas que no han sobrevivido?, ¿cuándo se habla de un asesinato y cuándo de una baja?, ¿qué implica el término posconflicto o posacuerdo?

Precisamente, en el documental Las voces del Cauca, se hace la aproximación a las discusiones sobre ¿qué tipo de violencia puede ser considerado como una masacre y por qué las familias de las víctimas de los asesinatos selectivos luchan por nombrar estos crímenes como masacres? Algunas pistas que permiten aclarar las razones de dichos esfuerzos por nombrar correctamente y visibilizar las injusticias y las atrocidades de la guerra están contenidas en el Informe General del Centro Nacional de Memoria Histórica (CNMH, 2013, p. 45).

Aunque este tipo de violencia tiende a ser subregistrada o a pasar desapercibida en el plano informativo nacional, con excepción de los magnicidios, algunas iniciativas de memoria de las víctimas denuncian estas acciones para hacer visibles los dramas individuales y la magnitud de la violencia selectiva. Las víctimas de Trujillo, Valle del Cauca, nombran hoy como 'masacre' no un evento concreto sino la violencia sistemática perpetrada por una alianza de narcotraficantes, paramilitares y miembros de la Fuerza Pública entre 1986 y 1994. Esta alianza cometió asesinatos selectivos, desapariciones forzadas y otros actos de violencia con sevicia en la clandestinidad. Al usar la etiqueta de masacre, los habitantes de Trujillo se proponen llamar la atención nacional frente a las reales dimensiones de lo sucedido.

El documental permite de alguna manera percibir las dimensiones de injusticias y atrocidades cometidas durante las masacres. En los testimonios de los familiares y los sobrevivientes de la masacre de Trujillo, al igual que de la masacre del Naya (el documental La Tierra Floreciente) se visibiliza el inmenso dolor y sufrimiento 
humano. En estos dos documentales, resaltan los testimonios sobre la sevicia de los paramilitares, en particular el descuartizamiento de los civiles, adultos y niños, como un método de violencia extrema, que no solamente aniquila las víctimas, sino causa un terror eterno en los sobrevivientes. El Grupo de Memoria Histórica hace énfasis en que:

Realizar actos violentos con sevicia y torturar fueron elementos determinantes para el proyecto paramilitar. Así lo atestigua la alta recurrencia y la inclusión de estas prácticas en el entrenamiento militar de los combatientes a través las denominadas "escuelas de descuartizamiento" o "escuelas de la muerte" [...]. La incorporación de la crueldad extrema en el repertorio de violencia paramilitar contribuyó a la construcción de una reputación terrorífica. Esta se convirtió en una caja de resonancia lo suficientemente eficaz como para dar credibilidad a sus amenazas y para demostrar el límite de violencia que estaban dispuestos a rebasar con el propósito de competir por el territorio. La reputación de violencia buscaba instalar el miedo en la sociedad para romper los vínculos entre la población civil y la guerrilla, y luego restablecerlos de otro modo, en función de sus intereses estratégicos. (CNMH, 2013, p. 56)

Los jóvenes realizadores no se limitan a la tarea de documentar lo sucedido, sino van más allá en la construcción de la memoria, cuyo deber vinculan con la necesidad de repensar lo sucedido en función de un presente y un porvenir distintos, pacíficos y justos. En la pantalla, se insiste en los poderes terapéuticos que tiene la expresión, sobre todo artística, que propicia el diálogo y la reconciliación, así como la cercanía con la naturaleza, constituida en el cultivo de la tierra. Gracias a la representación de estas experiencias, en medio de las imágenes de horror de la guerra, se filtra una luz de esperanza.

\section{Complejidad de la violencia. Denuncias simbólicas}

La coherencia entre un condensado y repetitivo contenido visual y sonoro (con el uso del archivo resignificado), presentado en otros formatos de forma dinámica, con un excelente manejo de ritmo y tensión, permite construir un retrato simbólico y mediatizado de Colombia, gracias a la creatividad de los realizadores que se aplica en función de hacer fuerte crítica a la pérdida de valores en medio de la violencia y las políticas multinacionales (neoliberales), reforzadas por los medios de comunicación al servicio de esas multinacionales (bombardeo informativo sin profundidad, atrofiado, fragmentado, alejado de la realidad y las problemáticas humanas, manipulado). Se visibiliza una complicidad en violencia entre el Gobierno, las guerrillas, los paramilitares y las fuerzas externas, así como la responsabilidad compartida por los crímenes de guerra, enfatizando en la elevación del dinero como un valor supremo que propicia la cosificación del ser humano. Además, en el fondo, se cuestiona la indiferencia de la humanidad frente al dolor y sufrimiento del prójimo.

\section{Llamado por la búsqueda de soluciones para terminar el conflicto}

El título del Informe ;Basta ya! Colombia: memorias de guerra y dignidad podría ser extendido a dicha selección de videos universitarios sobre la problemática del conflicto armado, teniendo en cuenta que refleja la esencia del discurso, contenido en estas obras, que enfatizan en la necesidad de la próxima culminación del conflicto, la dignificación de las víctimas y la reconciliación, lo cual es imposible de lograr sin la reconstrucción de la memoria colectiva.

\section{Hallazgos}

En la tabla 2, se muestra la síntesis de los resultados de la aplicación de la matriz de análisis a los 18 videos que presentan el conflicto armado de manera directa. 
TABLA 2

Matriz de análisis a 18 videos de presentación directa: síntesis de resultados

\begin{tabular}{|c|c|c|c|}
\hline \multicolumn{4}{|c|}{ Memoria del conflicto armado (presentación directa) } \\
\hline Formato & Cortometrajes de ficción & Documentales & $\begin{array}{l}\text { Otros formatos } \\
\text { (experimentales) }\end{array}$ \\
\hline $\begin{array}{l}\text { Universidad } \\
\text { (liderazgo) }\end{array}$ & $\begin{array}{l}\text { Universidad del Magdalena (Santa Marta) y } \\
\text { centros educativos de Bogotá (Universidad } \\
\text { Javeriana, Escuela Black Maria, Universidad } \\
\text { Manuela Beltrán, Universidad Nacional de } \\
\text { Colombia, Universidad de la Sabana) y de } \\
\text { Medellin, la Universidad de Antioquia. }\end{array}$ & $\begin{array}{l}\text { Universidad del Valle (Cali) y universidades de } \\
\text { Bogotá (Uniminuto, Universidad Nacional de } \\
\text { Colombia, Universidad Javeriana); de Popayán, } \\
\text { Universidad del Cauca; de Medellín, Universidad de } \\
\text { Medellín. }\end{array}$ & $\begin{array}{l}\text { Universidad del Valle (Cali) y } \\
\text { Escuela Black Maria (Bogotá) }\end{array}$ \\
\hline Palabras clave & $\begin{array}{l}\text { violencia, conflicto armado, muerte violenta, } \\
\text { sufrimiento }\end{array}$ & violencia, memoria colectiva, identidad & violencia, política \\
\hline $\begin{array}{l}\text { ¿Qué se } \\
\text { cuenta? }\end{array}$ & $\begin{array}{l}\text { Lucha entre el bien (víctimas, sociedad civil) y } \\
\text { el mal (victimarios, no especificados } \\
\text { claramente); diferentes modalidades de } \\
\text { violencia y fantasmas del pasado. Historias } \\
\text { sencillas (significado universal). Búsqueda de } \\
\text { compasión y sensibilización frente al dolor y } \\
\text { sufrimiento que trae la guerra. Un llamado por } \\
\text { la búsqueda de soluciones para terminar el } \\
\text { conflicte. }\end{array}$ & $\begin{array}{l}\text { Conflicto armado y sus consecuencias para los } \\
\text { ciudadanos; construcción de la memoria colectiva } \\
\text { (violencia, masacres, minas antipersonales, } \\
\text { desplazamientos forzados, deportaciones o los } \\
\text { referentes mediáticos comunes); indagación por la } \\
\text { identidad; vida cotidiana en medio del conflicto } \\
\text { armado. Ejemplos de superación de traumas del } \\
\text { conflicto gracias a la expresión artística o la cercania } \\
\text { con la naturaleza. }\end{array}$ & $\begin{array}{l}\text { Vínculos entre el poder político } \\
\text { y la violencia (montaje de } \\
\text { contrastes). Denuncia contra } \\
\text { los políticos hipócritas, la } \\
\text { violencia. la manipulación de } \\
\text { los medios de comunicación al } \\
\text { servicio de las multinacionales. }\end{array}$ \\
\hline Personajes & $\begin{array}{l}\text { Sociedad civil (los más vulnerables, nińos, pero } \\
\text { también ancianos y familias) }\end{array}$ & Mayoria jóvenes (presencia de la familia) & Personajes simbólicos \\
\hline Familia & $\mathrm{Si}$ (en la mayoría) & Si (en algunos casos) & $\begin{array}{l}\text { No (aunque simbólicamente se } \\
\text { muestra el sufrimiento de las } \\
\text { madres de las víctimas del } \\
\text { conflicto) }\end{array}$ \\
\hline $\begin{array}{l}\text { Narrativa } \\
\text { audiovisual }\end{array}$ & $\begin{array}{l}\text { Dramatizado: montaje de contrastes (realidad } \\
\text { violenta vs. pasado pacifico o lo que es vs. lo } \\
\text { que debería ser), fantasmas del pasado; énfasis } \\
\text { en la belleza de la naturaleza, actores y } \\
\text { escenarios naturales, silencios, detalles } \\
\text { (creación del efecto de la presencia). }\end{array}$ & $\begin{array}{l}\text { Testimonial: apoyada por el archivo. La importancia } \\
\text { de nombrar adecuadamente los hechos (caso de las } \\
\text { masacres) en el proceso de la búsqueda de la verdad y } \\
\text { la construcción de la memoria. }\end{array}$ & $\begin{array}{l}\text { Experimental: montaje de } \\
\text { contrastes, ausencia de palabras, } \\
\text { animación. }\end{array}$ \\
\hline Metáfora & $\begin{array}{l}\text { Diversas: secuestro (Colombia como un país } \\
\text { secuestrado), oposición entre la obra de la } \\
\text { naturaleza (belleza, armonía) y la obra del } \\
\text { hombre (guerra, destrucción), simbiosis de las } \\
\text { personas con la tierra. }\end{array}$ & $\begin{array}{l}\text { Diversas: simbiosis del cuerpo con la televisión; } \\
\text { simbiosis del cuerpo con el entorno; naturaleza } \\
\text { como el símbolo de vida, paz y prosperidad, en } \\
\text { oposición a las acciones del hombre - guerra, } \\
\text { destrucción y muerte; río Cauca como testigo: las } \\
\text { voces del Cauca, y lugar de la sepultura; arte como } \\
\text { remedio para curar los traumas de la guerra, el hecho } \\
\text { rebobinar los casetes audiovisuales como símbolo de } \\
\text { las constantes resignificaciones de la memoria } \\
\text { audiovisual. }\end{array}$ & $\begin{array}{l}\text { Cuerpo: cuerpos humanos } \\
\text { empacados al vacío listos para la } \\
\text { venta, los detalles de los cuerpos } \\
\text { de los personajes (Uribe, } \\
\text { Tirofijo, Mancuso, Castanoo) } \\
\text { presentados ensangrentados } \\
\text { consecutivamente; la } \\
\text { intervención quirúrgica en el } \\
\text { ojo que es obligado ver lo que } \\
\text { "debe ver" (manipulación } \\
\text { mediática). }\end{array}$ \\
\hline Archivo & $\begin{array}{l}\text { Ausencia del archivo (únicamente se usa en un } \\
\text { cortometraje sobre el Bogotazo) }\end{array}$ & $\begin{array}{l}\text { Importancia del archivo audiovisual, que junto con } \\
\text { el testimonio, se convierte en herramienta } \\
\text { fundamental de las narrativas y en apoyo importante } \\
\text { en la reconstrucción de la memoria audiovisual. }\end{array}$ & $\begin{array}{l}\text { Archivo resignificado, } \\
\text { intervenido, que no se usa como } \\
\text { archivo mismo, sino en función } \\
\text { del insumo para construir } \\
\text { nuevos significados. }\end{array}$ \\
\hline
\end{tabular}

Fuente: elaboración propia 
TABLA 2 (CONT.)

Matriz de análisis a 18 videos de presentación directa: síntesis de resultados

\begin{tabular}{|c|c|c|c|}
\hline \multicolumn{4}{|c|}{ Memoria del conflicto armado (presentación directa) } \\
\hline Formato & Cortometrajes de ficción & Documentales & $\begin{array}{l}\text { Otros formatos } \\
\text { (experimentales) }\end{array}$ \\
\hline Animación & No & $\begin{array}{l}\text { Si (poca: para reflejar el paso del tiempo, cambios de } \\
\text { los gobiernos (figuras animadas de los políticos) o } \\
\text { cambios en la vida (huellas de dos pies y de un solo } \\
\text { pie, después de pisar la mina). }\end{array}$ & $\begin{array}{l}\text { Si (base de la narrativa } \\
\text { simbólica-experimental) }\end{array}$ \\
\hline Lugar & campo (prevalece) & ciudad (prevalece) & $\begin{array}{l}\text { lugar simbólico (no } \\
\text { especificado) }\end{array}$ \\
\hline Tiempo & Presente/Varios tiempos & Varios tiempos & Presente \\
\hline $\begin{array}{l}\text { Referentes del } \\
\text { pasado }\end{array}$ & $\begin{array}{l}1948 \text { (el Bogotazo), } 1996 \text { (el escalamiento del } \\
\text { conflicto armado en Colombia); diferentes } \\
\text { modalidades de violencia características del } \\
\text { conflicto colombiano, letreros o inscripciones, } \\
\text { usados con el fin de atemorizar la población } \\
\text { civil: "Aprenden a las buenas o les enseñamos a } \\
\text { las malas" o "Guerrilleros Hijueputas". }\end{array}$ & $\begin{array}{l}\text { Masacre de Trujillo (1988-1994), Masacre del Naya } \\
\text { (2001), testimonios de las víctimas (asesinatos, } \\
\text { torturas, minas antipersonales, desplazamientos, } \\
\text { reclutamientos forzadas, deportaciones); época del } \\
\text { gobierno de Rojas Pinilla, programación televisiva } \\
\text { (1980-2004): archivo TV de noticieros televisivos: } \\
\text { conflicto armado, conversaciones de paz, apagón, } \\
\text { proceso "ocho mil”, tragedia de Armero, toma del } \\
\text { Palacio de Justicia, terror causado por Pablo } \\
\text { Escobar, muerte de Rodrigo Lara, visita del Papa } \\
\text { Juan Pablo II a Colombia, etc.; fragmentos de } \\
\text { telenovelas, series, reinados de belleza, concursos, } \\
\text { etc. }\end{array}$ & $\begin{array}{l}\text { Imágenes (video, TV) de } \\
\text { matanzas, muertos, heridos, } \\
\text { bombardeos; sonidos de los } \\
\text { disparos; personajes (Uribe, } \\
\text { Tirofijo, Mancuso, Castaño) } \\
\text { ensangrentados; una mujer con } \\
\text { el pan̂uelo; archivo sonoro con } \\
\text { el discurso de Álvaro Uribe } \\
\text { sobre la política de la seguridad } \\
\text { democrática, archivo } \\
\text { fotográfico y sonoro del } \\
\text { ESMAD; fotografia de las } \\
\text { protestas ciudadanas. }\end{array}$ \\
\hline $\begin{array}{l}\text { Valores } \\
\text { (universo } \\
\text { axiológico) }\end{array}$ & $\begin{array}{l}\text { Paz y vida pacífica, otros como: libertad, amor, } \\
\text { familia, amistad, arraigo a la tierra, trabajo en } \\
\text { el campo, educación o realización personal son } \\
\text { importantes, pero condicionados a la paz. }\end{array}$ & $\begin{array}{l}\text { Memoria colectiva; rechazo a la violencia, la } \\
\text { desigualdad y la injusticia; preocupación por las } \\
\text { identidades, recuperación de las traumas del } \\
\text { conflicto a través del arte y el contacto con la } \\
\text { naturaleza. }\end{array}$ & Paz y vida pacífica. \\
\hline $\begin{array}{l}\text { Aportes en la } \\
\text { construcción } \\
\text { de la memoria } \\
\text { colectiva }\end{array}$ & $\begin{array}{l}\text { Memorias de: violencia (traumática), } \\
\text { victimización, resistencia, cotidianidad, estilo } \\
\text { de vida, familia, intima, imaginarios, } \\
\text { fantasmagórica. } \\
\text { Énfasis: repensar la ética. }\end{array}$ & $\begin{array}{l}\text { Memorias de: identidad, violencia, victimización, } \\
\text { resistencia, traumática, intima, mediatizada, estilo } \\
\text { de vida, histórica, cierta época, (historia de vida), } \\
\text { cultural, imaginarios. } \\
\text { Énfasis: repensar la realidad. }\end{array}$ & $\begin{array}{l}\text { Memorias de: violencia, } \\
\text { victimización, resistencia, } \\
\text { simbólica, mediatizada, } \\
\text { cotidianidad, imaginarios. } \\
\text { Énfasis: repensar lo político. }\end{array}$ \\
\hline
\end{tabular}

Fuente: elaboración propia

El deber de memoria se substancia en el reconocimiento de que el sufrimiento es la condición de toda verdad o, dicho de otra manera, el deber de memoria consiste en repensarlo todo a la luz de la barbarie para hacer justicia a las víctimas y para que ese pasado no se repita. Los dos objetivos son inseparables. (Mate, 2012, pp. 44-45)

Precisamente, los jóvenes realizadores con sus trabajos audiovisuales emprenden la compleja tarea de repensar este "todo" nombrado por Manuel Reyes Mate. Sin embargo, en cada uno de los formatos parece centrarse en el abordaje de algunos aspectos específicos relacionados con la reconstrucción de la memoria colectiva. Los cortometrajes de ficción enfatizan en los cuestionamientos concernientes a las transformaciones de los valores en marco de la guerra, los documentales se sumergen en las realidades violentas y en la búsqueda de la verdad, mientras que los trabajos experimentales (otros formatos), al referirse directamente a la crítica de las sagaces alianzas entre los poderes económicos, políticos y mediáticos, plantean las denuncias frente a las injusticias y, aunque de manera simbólica, intentan formular acusaciones.

\section{Cortometraje de ficción. Repensar la ética}

Reyes Mate señala que en el fondo de repensar la ética está la pregunta formulada por Primo Levi:

'Si esto es un hombre' [...] una pregunta inquietante pues de su respuesta no sólo (sic) depende la humanidad del otro, sino del que responde. Están en juego las cadenas del otro, pero también las nuestras, hasta el punto de que sólo (sic) liberando al otro nosotros alcanzaremos la libertad. (Mate, 2012, p. 54) 
Los trabajos audiovisuales de ficción no pretenden incriminar o hacer los juicios concretos, sino aspiran a revelar la complejidad de la condición humana en general: mostrar al hombre (desde las subjetividades), involucrado por años en una guerra, donde los principales valores humanos como la vida, libertad, amor, familia, amistad, trabajo, estudio, arraigo a la tierra, están condicionados por el valor supremo que es la paz. Sin paz otros valores parecen ser inalcanzables.

La pregunta principal por el hombre, conlleva a otras, entre ellas: ¿es posible que un hombre prepare este destino a otro hombre?, ¿llegamos al momento cuando la violencia y la guerra se convirtieron en la cotidianidad?, ¿el hombre puede acostumbrarse a la guerra, con-vivir con ella sin perder la esencia de ser humano?, ¿cómo vivir después de traicionar o matar a su hijo, vecino, prójimo, adversario? Los realizadores como mediadores entre las realidades resignificadas (previamente vividas, investigadas, contadas) y los públicos, asumen la tarea de traductibilidad de los complejos cuestionamientos éticos, por los cuales atraviesa a diario la sociedad colombiana, a unas históricas concisas con el objetivo de sensibilizar al espectador y lograr la compasión como si se tratase de poemas audiovisuales, que evitan los diálogos, y en medio de las metáforas visuales acompañadas por la música, reconstruyen las luchas o disputas entre el bien y el mal, la paz y la guerra, la belleza natural y la violencia de los hombres.

Documentar audiovisualmente el conflicto armado que a diario se desarrolla en el campo colombiano es prácticamente imposible para los universitarios por falta de seguridad, miedos, dificultades técnicas o de financiación, lo que los lleva a trasladar esta problemática al lenguaje metafórico de la ficción (narrativa dramatizada). Sin embargo, las ficciones sobre el conflicto armado están ligadas a las realidades y las memorias de la guerra, sobre todo a través de las representaciones de diferentes modalidades y prácticas características de los actores del conflicto armado en Colombia, aunque estas sirvan únicamente de pretexto para ir más allá en la indagación por la condición humana, con toda la complejidad de relaciones humanas que se activan en las situaciones límite.

En algunos cortometrajes, aparecen los "fantasmas del pasado" que no dejan que los personajes tengan el presente o el futuro tranquilos. La inclusión de estos elementos en las narrativas refleja la preocupación de los jóvenes por la búsqueda de la verdad y reconciliación. Asimismo, en las obras de ficción que manejan los tiempos de acción o de historia más extensos suelen abordarse las transformaciones de los personajes, lo que permite profundizar en la complejidad del ser humano. Los sufrimientos de las víctimas se entretejen con los sufrimientos de los victimarios que además de hacer daño a las víctimas, se han hecho daño a sí mismos. El hecho de acudir a la venganza o respuesta violenta frente a la violencia se muestra en la pantalla como la peor alternativa, que solamente agudiza el conflicto sin solucionar nada. Ante los espectadores aparece un mensaje implícito por la responsabilidad de cada uno por lo que pasa alrededor y una exigencia de repensar la ética, teniendo en cuenta que "el ser humano es una conquista, una tarea en la que podemos fracasar" (Mate, 2012, p. 55).

\section{Documental. Repensar la realidad}

El proceso de la construcción y comprensión del presente y del futuro depende en gran medida de la memoria. Uno de los aspectos sustanciales de este proceso es constantemente repensar la realidad que consiste en:

[...] no confundir la realidad con la facticidad. La facticidad es la parte del pasado que ha triunfado y ha llegado hasta nosotros, pero de la realidad también forma parte aquello que pudo ser y quedó eliminado, los sin-nombres, los perdedores, los aplastados, los olvidados. (Mate, 2012, p. 46)

Es aquí donde la figura de la víctima toma una especial importancia desde la perspectiva de la experiencia que ella comparte con el fin de no repetición; una experiencia traumática, de sufrimiento, con frecuencia silenciada por diferentes factores, como el miedo a la represión, la autosugestión o las esperanzas de olvidar y no revivir lo sucedido. 
Las narrativas de todos los documentales en cuestión están basadas en los testimonios de las víctimas o personas que han participado en los hechos que se relatan o reconstruyen en la pantalla, relacionados con la vida diaria en medio de la guerra, las masacres, los desplazamientos, las deportaciones, las desapariciones o las minas antipersonales. Los documentales indagan por la verdad, participan en la construcción de la verdad, en la visibilización de lo oculto o ausente en el relato oficial, entretejiendo en sus narrativas los testimonios de sufrimiento, los ejemplos de extraordinaria resistencia, las luchas por nombrar los hechos según su verdadero nombre, con las propuestas (personales, colectivas, ciudadanas, estatales) de la construcción de un futuro pacífico, asociadas a las expresiones artísticas y la cercanía con la naturaleza. El arte y la convivencia con la naturaleza se presentan como poderes curativos. La estética de detalle, que aumenta la sensación y el efecto de la presencia, unidas a las sensibilidades de los jóvenes realizadores, dispuestos a experimentar con las herramientas narrativas y estéticas crean obras que incitan al público para repensar la realidad y preguntarse por la responsabilidad de cada uno en lo sucedido y por suceder.

\section{Video experimental. Repensar la política}

En las obras experimentales, se articulan los discursos simbólicos que cuestionan las políticas neoliberales, cuya idolatría del consumo lleva a los niveles impensables de convertir al ser humano en simple mercancía, con las críticas concretas dirigidas en contra del conflicto armado o la implementación de la política de seguridad democrática, alejada de los principios de la democracia y la ciudadanía. Los estudiantes en medio del montaje intelectual crean contrastes que representan los abismos existentes en las sociedades contemporáneas entre los dirigentes y el pueblo, las ambiciones e indiferencia de los políticos y el sufrimiento de las víctimas, los ricos y los pobres, los países del primer y del tercer mundo, los intereses particulares y el bien común. Falta de respeto por la naturaleza y los bienes naturales, expresada en el extractivismo, reforzado por la omnipresencia de los medios de comunicación al servicio de las empresas multinacionales que destruyen sin piedad el medio ambiente, son centrales en dichos discursos universitarios que proponen repensar la política que consiste en “[...] saber distinguir entre un progreso que está al servicio de la humanidad, de la humanización del hombre, y otro progreso que convierte a esa humanidad en instrumento para el progreso" (Mate, 2012, p. 48).

En la construcción de la mirada crítica frente a los medios de comunicación, se infiltran las preocupaciones de los jóvenes realizadores por su propio quehacer como profesionales que probablemente en un futuro cercano se desempeñarán en los medios masivos de comunicación. Aunque estos autocuestionamientos se visibilizan con mayor fuerza en los trabajos experimentales, atraviesan las narrativas de todos los formatos y de alguna manera expresan la inquietud por la construcción del futuro y el lugar de los jóvenes en él.

Se hace evidente que los estudiantes se involucran en la construcción de los discursos sobre la violencia con un claro propósito de aportar a la construcción de la memoria colectiva y del mejor futuro. "Nada es irreversible, y las condiciones democráticas humanistas deben regenerarse de manera permanente, de lo contrario degeneran. La democracia necesita recrearse de manera permanente. Pensar la barbarie es contribuir a recrear el humanismo. Por lo tanto, es resistirse a ella" (Morin, 2009, p. 94).

\section{Conclusiones}

Las narrativas audiovisuales universitarias no son homogéneas, además están fuertemente mediadas por las instituciones de donde provienen, sin embargo, en lo relativo a los referentes históricos, el conflicto armado en Colombia se perfila como eje articulador de sentido y su tratamiento audiovisual se desarrolla desde la profundización en las esferas de sufrimiento y dolor, a partir de las aproximaciones a experiencias y sensibilidades concretas que por su enfoque humanístico pueden tener una lectura universal. Los trabajos que abordan la problemática de memoria del conflicto armado están atravesados por una exigencia expresa 
de los realizadores de devolverle a las palabras y los conceptos su verdadero sentido, de nombrar las cosas por su nombre, de acortar la distancia entre los pronunciamientos y las realidades y entre las promesas y las prácticas, de visibilizar lo invisibilizado, de contar lo silenciado, de expresar lo intangible, de resistir al olvido, no desde la persecución de una verdad absoluta, sino desde la búsqueda del diálogo alrededor de la pluralidad de verdades y puntos de vista.

Se podrían plantear algunos cuestionamientos o reclamos a los realizadores frente a la tendencia a esquivar las indagaciones por las causas del conflicto armado o por evitar la exploración y el seguimiento de referentes históricos de fondo, pero dichos aspectos parecen no ser prioritarios para los estudiantes. Es como si de alguna manera quisieran trasladar el centro de atención, desde las interminables disputas sobre la culpabilidad a una consolidación discursiva, orientada a la necesidad de repensar la memoria colectiva desde la ética, apoyándose en la representación de diversas realidades, vividas y experimentadas aquí y ahora, apostando a una especie de tregua con el pasado que no puede ser cambiado, lo que en las narrativas audiovisuales universitarias conceptualmente converge en un llamado común por la urgente finalización del conflicto armado, exteriorizado en la pantalla desde la perspectiva de la barbarie.

En el marco de este laboratorio de construcción de sentido a través de las narrativas audiovisuales universitarias, se hace una gran apuesta por el testimonio, convirtiéndolo en la herramienta principal de vehiculización al pasado, así como al presente y al futuro, deseables. Las narrativas audiovisuales documentales sobre las memorias del conflicto armado están basadas en el testimonio que, en el caso de los relatos autobiográficos de los jóvenes realizadores, toma forma de un monólogo íntimo. La priorización del testimonio influye en el fortalecimiento de la subjetividad en el discurso, dedicado a la reconstrucción del pasado del país, discurso que valora las expresiones de presencia, experiencia, vivencia, percepciones, emociones, sentimientos y deseos.

El archivo en sus múltiples modalidades: fotográfico, televisivo, cinematográfico, sonoro o de internet, y en el caso de los videos experimentales intervenido, sigue presente en las narrativas audiovisuales como un elemento propio en la reconstrucción del pasado. Para evidenciar el sufrimiento, en el cual ha sido sumergido el país por años a causa del conflicto armado, se acude a recrear en la pantalla múltiples metáforas, relacionadas con el dolor, como por ejemplo, la metáfora del país secuestrado o del río Cauca convertido en el lugar de sepultura y, por ende, en una víctima más de violencia que se opone al silenciamiento a través del testimonio, proveniente del sonido de sus aguas, en el cual convergen las voces de los muertos desconocidos que exigen ser nombrados y recordados. El olvido, el ocultamiento de la verdad, la falta de visibilización y del debate alrededor del pasado también encuentran su representación metafórica en forma de una omnipresente neblina que impide ver lo que pasa alrededor o en la presentación del apagón eléctrico, no desde la perspectiva de un ahorro, sino como limitación forzada del acceso a luz y a los medios de comunicación y, por lo tanto, en la comprensión de la realidad y su recordación. Mostar en la pantalla el hecho de rebobinar constantemente las grabaciones audiovisuales del archivo advierte sobre los peligros de la manipulación de la memoria, sobre todo de la mediática.

La construcción de lo deseable desde las narrativas audiovisuales universitarias impacta a la esfera de valores, donde la paz y la vida pacifica se muestran en calidad de valores supremos que condicionan otros como la vida misma, la libertad, el amor, la familia, la amistad, el arraigo a la tierra, el trabajo en el campo, la educación, la realización personal y el respeto por la diversidad. Según los discursos de los jóvenes, la paz está condicionada por los complejos procesos de autorreflexión que involucran la reconstrucción de la memoria colectiva, basada en recuperación del respecto por la multiplicidad de miradas, por diferentes estilos de vida y formas de relacionarse con el mundo. Se hace un llamado al repensar colectivo de la ética, realidad y política, con el fin de aproximarse a lo deseable.

La variedad de personajes que aparecen en la pantalla, de diferentes edades, procedencias étnicas y culturales, de distintos estilos de vida, con miradas opuestas, víctimas y victimarios refleja las intenciones de los jóvenes de contar el país diverso, multifacético, auténtico. Y aunque el aporte de los realizadores universitarios 
en reconstruir las memorias colectivas de sus habitantes es evidente, el fortalecimiento de dicha tarea se perfila como uno de los grandes retos para las universidades.

\section{Referencias}

Carrithers, M. (1995), ¿Por qué humanos tenemos cultura? Una aproximación a la antropología y la diversidad social. Madrid: Alianza.

Centro Nacional de Memoria Histórica (CNMH). (2013). ¡Basta ya! Colombia: memorias de guerra $y$ dignidad (Informe General). Bogotá: Centro Nacional de Memoria Histórica. Recuperado de http://www.centrodememoriahistorica.gov.co/descargas/informes2013/bastaYa/basta-ya-colombia-memo rias-de-guerra-y-dignidad-2016.pdf

Colmeiro, J. (2005). Memoria histórica e identidad cultural: de la posguerra a la postmodernidad. Barcelona: Anthropos Editorial.

Cubides, J. (2011). Jóvenes y política ¿de objetos a sujetos de política? En F. Acosta, J. Cubides y L. Galindo, Sentidos $y$ prácticas politicas en el mundo juvenil universitario (pp. 21-40). Bogotá: Universidad Nacional de Colombia.

Halbwachs, M. (2005). La memoria colectiva. Zaragoza: Ediciones Universitarias de Zaragoza.

Herrera, J. D. (2010). La comprensión de lo social. Horizonte hermenéutico de las ciencias sociales. Bogotá: Fundación Centro Internacional de Educación y Desarrollo Humano.

Mate, M. (2012). Memoria de la barbarie y construcción del futuro. Barcelona: Ediciones Generalitat de Catalunya.

Moretti, F. (2007). La literatura vista desde lejos. Barcelona: Marbot Ediciones.

Morin, E. (2009). Breve historia de la barbarie en Occidente. Barcelona: Paidós.

Ricoeur, P. (2008). La memoria, la historia, el olvido. Buenos Aires: Fondo de Cultura Económica.

Vich, V., y Zavala, V. (2004). Oralidad y poder. Herramientas metodológicas. Bogotá: Norma.

\section{Notas}

* Artículo de investigación científica.Se presentan los resultados parciales de la investigación "Itinerarios de la memoria colectiva del país en las narrativas audiovisuales universitarias colombianas: Muestra Ventanas 2005-2014”, realizada por la autora en el marco del Doctorado en Ciencias Sociales y Humanas de la Pontificia Universidad Javeriana (2013-2017).

\section{Licencia Creative Commons CC BY 4.0}

Cómo citar este artículo: Urbanczyk, M. (2019). La construcción de la memoria colectiva del conflicto armado en Colombia desde el video universitario (2005-2014). Signo y Pensamiento, 38(75). https://doi.org/10.11 144/Javeriana.syp38-75.cmcc 